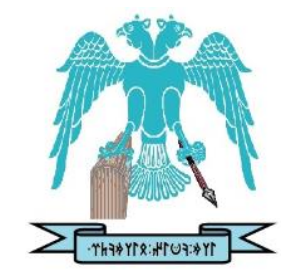

JOURNAL OF ENERGY SYSTEMS

$2021,5(1)$

\title{
Modeling of doubly fed induction generator based wind energy conversion system and speed controller
}

\author{
Endalew Ayenew Haile \\ Adama Science and Technology University, School of Electrical Engineering and Computing, Electrical \\ Power and Control Engineering, Adama, Ethiopia, endalewayenew@ gmail.com
}

Getachew Biru Worku

Adama Science and Technology University, School of Electrical Engineering and Computing, Electrical Power and Control Engineering, Adama, Ethiopia, gbiru@ yahoo.co.uk

Asrat Mulatu Beyene

Addis Ababa Science and Technology University, Center of Excellence for Sustainable Energy, Addis Ababa, Ethiopia, asrat.mulatu@aastu.edu.et

Milkias Berhanu Tuka

Adama Science and Technology University, School of Electrical Engineering and Computing, Electrical Power and Control Engineering, Adama, Ethiopia, milkiasber@gmail.com

$\begin{array}{rr}\text { Submitted: } & 09.01 .2021 \\ \text { Accepted: } & 07.03 .2021 \\ \text { Published: } & 31.03 .2021\end{array}$

Abstract: In this paper, modeling of doubly fed induction generator (DFIG) based wind energy conversion system (WECS) and generator speed controller are presented. The System Identification Toolbox of MatLab is used to develop the linear model of the WECS by considering the wind speed as input and speed of the generator as output. Two models, namely Auto Regressive with eXogenous Input (ARX) and Auto-Regressive Moving Average with eXogenous Input (ARMAX), are estimated. We used the ARX221 model structure with the best fit of $84.31 \%$, Final Prediction Error (FPE) of 0.0433 and Mean Square Error (MSE) of 0.0432. The Ziegler-Nichols (Z-N) method and the fuzzy logic technique are employed in the proportional integral derivative (PID) controller design to control the speed of the generator. The classical Z-N PID used for the responses of the system is observed to be insufficient for both uniform and variable inputs, hence, a better response has been obtained by applying the fuzzy logic-based PID controller. The present study proves that the fuzzy logic based control enhances the speed regulation of generator in the WECS by overcoming the effect of varying wind speed.

Keywords: Fuzzy logic, PID, Speed control, WECS model, Ziegler-Nichols method

Cite this paper as:

Haile, E.A., Worku, G.B., Beyene, A.M., \& Tuka, M.B., Modeling of doubly fed induction generator based wind energy conversion system and speed controller. Journal of Energy Systems 2021, 5(1), 46-59, DOI: $10.30521 /$ jes.854669

(C) 2021 Published by peer-reviewed open access scientific journal, JES at DergiPark (https://dergipark.org.tr/en/pub/jes) 


\section{INTRODUCTION}

Wind energy is an abundantly available renewable energy source. Comprehensive knowledge about the wind features is required for an efficient energy generation. The conversion of energy from wind is stochastic due to variations in wind speed. The mathematical model of Wind Energy Conversion System (WECS) is highly affected by the wind conditions. This begs for an appropriate model estimation technique to characterize the phenomenon of WECSs. A double-fed induction generator (DFIG) based an upward oriented horizontal axis wind turbine is dominantly applicable to convert the mechanical energy to the electrical one in WECSs. By controlling the speed of DFIGs through controlling the pitch angle of wind turbine blades, it is possible to regulate the output power of the wind turbine generator to a rated value even for higher wind speeds.

Naturally, the mathematical model of WECSs is nonlinear. Higher order nonlinear and linearized mathematical models of WECSs was discussed in Ref. [1]. From the literature, nonlinear AutoRegressive Moving Average with eXogenous input (NARMAX) structure based mathematical model of WECSs was presented in [2] and [3]. In [4] applying interpolation of NARMAX was expressed as ARMAX structure. The ARMAX model shown in [5] was simpler than the NARMAX model depicted in [2] and [3] for the practical implementations. These models were well-validated by using best-fit percentage, final prediction error (FPE), and mean square error (MSE) values as the evaluation criteria $[2,3,4,5,6,7]$. The estimated models should have high fit percent, very small FPE and MSE. ARX model structure for the temperature process plant got model validation criteria of best fit of 99.19\%, FPE of 1.002, and MSE of 0.05 as discussed in Ref. [8]. However, the model quality was not acceptable for the practical implementations due to its large FPE value. In MatLab documentations to resolve fit value difference in model identification and retire initial ARMAX model, simulation fits of their models were found as $70.56 \%$ to $76.44 \%$ and $72.4 \%$ to $81.25 \%$, respectively. Indeed, they were considered as the indicators of model quality [9]. The linear models used in the heating system were ARX, ARMAX and Box-Jenkins (BJ) with the estimated model simulations output fit to measured data are $69.64 \%, 75.23$ $\%$ and $91.03 \%$. These results were ideal. However, even if the BJ model structure was the best fit, it contained four polynomials of different orders, hence its implementation was limited due to its complexity [10].

The WECS mathematical models described above were complex and demanded complex controllers. To overcome this limitation, the identification technique used in this work enables the design of lowerorder models. We have used a doubly-fed induction generator based the WECS Model. Considering the subsystem model for low wind speed, the estimated ARX model of turbine torque is fitted to $73.72 \%$, and for medium wind speed, it is fitted to $65.79 \%$ with large FPE and MSE in both cases [11].

In Ref. [12], a speed controller was proposed to extract the maximum power from wind turbines. Regulating the speed of the generator in the WECSs by using a robust speed controller was presented in [13]. It improved the power capturing ability of wind turbines by using a slide mode speed controller. As described in Ref. [14], WECSs were classified as either power control or speed control. Variable speed WECSs have also been used due to their decoupling ability of power generating system from grid frequency and rotational speed adaptability according to recent literature. Hala and co-workers [15] designed a PI controller to control the speed of DFIG based WECS [15]. However, they did not consider wind speed variations in their model. Many researchers proposed speed controller of generator as it improved the generator output power and system frequency $[1,16,17]$. The simulation results of wind turbine maximum power point tracking controlled by a deep neural network technique indicated $33 \%$ overshoot with a better final value [18]. Comparative analyses of such controllers and fuzzy logic based controllers for the maximum power point tracking were presented in Ref. [19]. The simulation results of direct field oriented control of DFIG speed resulted in variations between $100-200 \mathrm{rad} / \mathrm{s}$, which showed high oscillation, and less reliability [20]. In addition, the responses under the wind turbine rotor speed between 1000 - 1450 rpm were explored in Ref. [21]. 
The present work aims to estimate a suitable model of DFIG based WECS and design generator speed control for the wind energy plant operating in standard conditions. For the WECS model representation, the simplest model structure called Auto Regressive with eXogenous inputs (ARX) is considered. For this model, a soft computing-based PID controller is designed. Its simulation results are compared with that of a classically designed PID controller.

\section{MODELING THE WIND ENERGY CONVERSION SYSTEM}

For the WECS model, the following assumptions are made:

Upward yaw orientation of variable speed Horizontal Axis Wind Turbine (HAWT) with three blades excluding the yaw mechanism.

One degree of freedom to drive the train of the rotating system. Oscillations of the towers and blades are not taken into acccount.

The power conversion coefficient is empirically estimated. Collective variable pitch mechanism of the blade regulates wind speed greater than the rated value. Tip speed ratio of HAWT and detailed dynamics of generator is not considered.

The mathematical model of the DFIG based WECS is presented using Eqs. (1-5). As in Ref. [22], the output power of the wind turbine rotor is given by,

$$
P_{m}=0.5 \rho \pi R^{2} C_{p}(\lambda, \beta) V_{m}^{3}
$$

where,

$$
\begin{gathered}
C_{p}(\lambda, \beta)=0.5176\left(\left(116 / \lambda_{t}\right)-0.4 \beta-5\right) \exp \left(-21 / \lambda_{t}\right)+0.0068 \lambda \\
1 / \lambda_{t}=1 /(\lambda+0.08 \beta)-0.035 /\left(1+\beta^{3}\right) \\
\lambda=\omega R / V_{w} \\
\beta=0.667 \tan ^{-1}\left(V_{w} / \omega r\right)-\alpha
\end{gathered}
$$

Here, $P_{m}$ is mechanical power, $V_{w}$ is wind speed, $R$ is a fixed radius of the blade, $\lambda$ is tip ratio of the wind turbine blade, $\beta$ is pitch angle, $C_{p}(\lambda, \beta)$ is wind to mechanical power conversion coefficient, $r$ is the fraction of $R, \omega$ is turbine rotor speed, $\alpha$ is angle of attack. In a typical WECS, an electrical generator with wind turbines through the drive train is mathematically described in [17]. The dynamic motion of the generator torque and rotational speed are interrelated by,

$$
T_{g}=J_{g} \frac{d w_{g}}{d t}+\beta_{g} w_{g}+T_{e}
$$

where, $T_{g}, \mathrm{~J}_{\mathrm{g}}, \beta_{\mathrm{g}}$, and $\omega_{\mathrm{g}}$ represent mechanical torque, equivalent inertia reduced to generator side, twistrigidity reduced to generator side and generator speed, respectively. 
The nominal model of the WECS is generated by using the model identification toolbox. The nominal wind speed is considered as $13 \mathrm{~m} / \mathrm{s}$ with a variance of $1.2 \mathrm{~m} / \mathrm{s}$. Using the specifications in Table 1, Eqs. (1-5), and the system identification technique, we have developed the model of the WECS as shown in Fig. 1. One of the advantages of using this technique is the ability to determine a linear discrete model for an equivalent nonlinear and complex physical system. Fig. 2 shows the input and output of the WECS. At a rate of 0.1 seconds per sample, 4000 training and validation data has been produced. This data is divided into two forms. Data between 1 and 2000 is used to approximate the model, whereas the rest between 2001 and 4000 is studied for the model confirmation.

Table 1. DFIG based wind energy conversion plant specifications [23].

\begin{tabular}{|c|c|c|}
\hline & Specifications & Values \\
\hline \multirow{8}{*}{$2 \mathrm{MW}$ Horizontal Axis Wind Turbine Rotor } & Number of Blades & 3 \\
\hline & Cut in speed $(\mathrm{m} / \mathrm{s})$ & 4 \\
\hline & Cut out speed $(\mathrm{m} / \mathrm{s})$ & 25 \\
\hline & Nominal speed $(\mathrm{m} / \mathrm{s})$ & 13 \\
\hline & Air density $\left(\mathrm{kg} / \mathrm{m}^{2}\right)$ & 1.225 \\
\hline & Rated rotor speed (rpm) & 14.9 \\
\hline & Dynamic rotor speed range (rpm) & $9.6-17$ \\
\hline & Blade diameter $(\mathrm{m})$ & 90 \\
\hline \multirow{4}{*}{ Drive Train } & Gear ratio & 1: 112.8 \\
\hline & Turbine inertia $\left(\mathrm{kg} \mathrm{m}^{2}\right)$ & $2 \times 10^{6}$ \\
\hline & Low speed shaft twist-rigidity $(\mathrm{Nm} / \mathrm{rad})$ & $160 \times 10^{6}$ \\
\hline & Low speed shaft twist-damper ( $\mathrm{Nm} \mathrm{s} / \mathrm{rad})$ & $1.6 \times 10^{5}$ \\
\hline \multirow{7}{*}{ Double Feed Induction Generator } & Rated power (MW) & 2 \\
\hline & Maximum generator speed (rpm) & 1680 \\
\hline & Generator max speed limit (pm) & 2900 \\
\hline & Generator terminal voltage (volt) & 690 \\
\hline & Rated frequency $(\mathrm{Hz})$ & 50 \\
\hline & Generator inertia $\left(\mathrm{kg} \mathrm{m}^{2}\right)$ & 60 \\
\hline & Generator torque $(\mathrm{k} \mathrm{Nm})$ & 13.4 \\
\hline
\end{tabular}
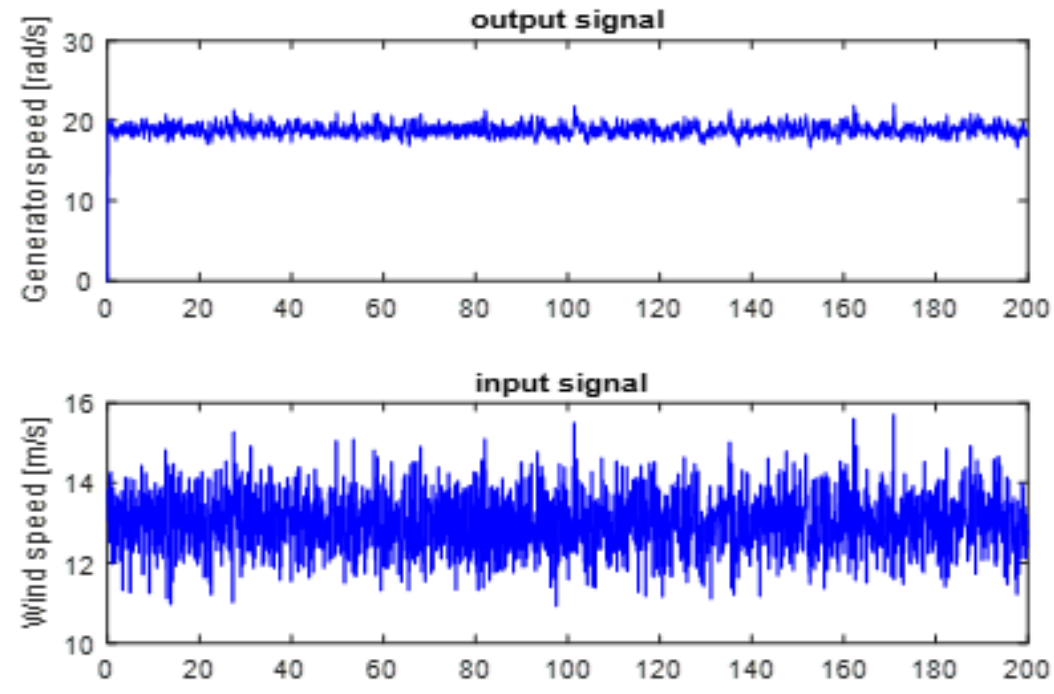

Figure 1. Data for WECS Model Estimation and Confirmation.

Table 2. Mean wind speed at 40 meters above measured in 2018 at Adama wind farm of Ethiopia. All values are in $\mathrm{m} / \mathrm{s}$.

\begin{tabular}{ccccccc}
\hline Jan & Feb & Mar & Apr & May & Jun & Jul \\
\hline 11.493 & 10.729 & 8.515 & 8.191 & 8.530 & 10.035 & 10.611 \\
\hline
\end{tabular}


A real-time wind speed data is collected and the monthly average value is tabulated in Table 2 . This data is used to develop the WECS model and final to test the model response for validation.

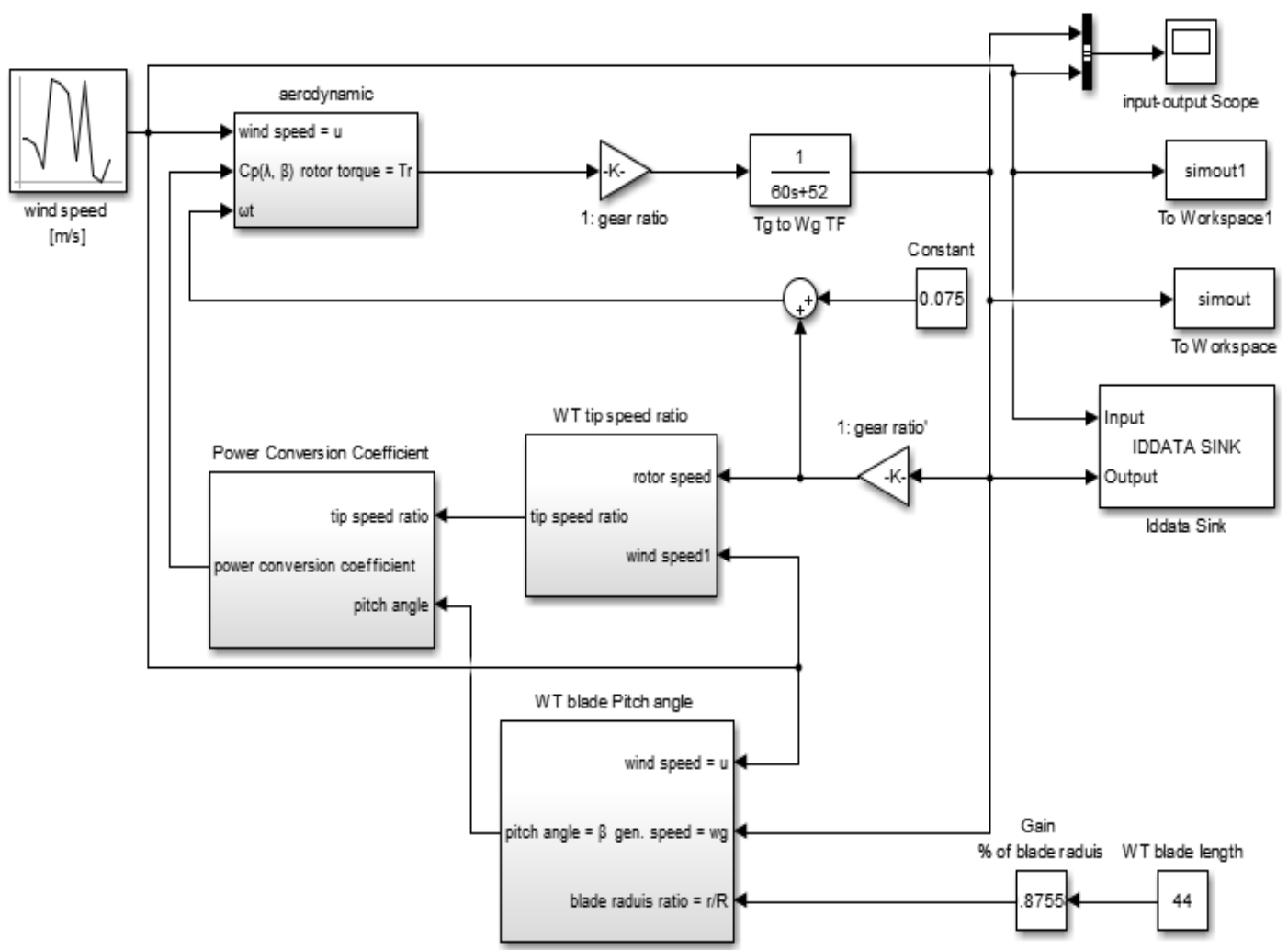

Figure 2. DFIG based WECS Simulation Model

Different models that relate the wind speed with the DFIG speed are identified and presented in Table 3. Model estimation needs acceptable precision to examine the WECS and develop the right speed regulator. In this study, best-fit performance (FPE and MSE), and model simplicity (Linear Model Representation) are considered as the criteria to choose the better model from the list in Table 3. Moreover, a validation test for the selected model is carried out.

ARMAX4441 is among the most popular models to characterize the WECS. As indicated in Table 3 the performances of this model are measured using best-fit, final prediction error, and mean square error. The results obtained are $84.91 \%, 0.0442$ and 0.0443 , respectively. This is compared with the result in [11], which shows better quality. The performance of ARMAX and ARX models are similar but as model structure increases the complexity also increases. Hence, it is right to choose ARX221, since it is the simpler model. This model can be described as;

$$
A(z) \omega_{g}(z)=B(z) V_{w}(z)+\xi(z)
$$

Where $\omega_{g}(z), V_{w}(z)$, and $\xi(\mathrm{z})$ are generator speed, wind speed, and disturbances in the discrete-time domain, respectively. Considering zero states at the beginning, Eq. (7a) presents the discrete transfer function of WECS and Eq. (7b) shows the equivalent continuous-time transfer function.

$$
\begin{gathered}
G(z)=\frac{\omega_{g}(z)}{V_{w}(z)}=\frac{0.6333 z^{-1}-0.004303 z^{-2}}{1-0.4597 z^{-1}-0.01125 z^{-2}} \\
G(s)=\frac{8.666 s+347.9}{s^{2}+44.87 s+305}
\end{gathered}
$$


For the linearized WECS models, as shown in Table 3 and plotted in Fig. 3, the corresponding curve fit is $84 \%$ for all the identified model structures.

Table 3. Discrete linear model structures for DFIG based WECS relating wind speed with generator speed.

\begin{tabular}{|c|c|c|c|c|c|}
\hline № & Model Structure & Best Fit $(\%)$ & FPE & MSE & Linear Model Representation \\
\hline 1 & ARX221 & 84.31 & 0.0433 & 0.0432 & $\begin{array}{l}\mathrm{A}(\mathrm{z})=1-0.4597 \mathrm{z}^{-1}+0.01125 \mathrm{z}^{-2} \\
\mathrm{~B}(\mathrm{z})=0.6333 \mathrm{z}^{-1}-0.004303 \mathrm{z}^{-2}\end{array}$ \\
\hline 2 & ARX231 & 84.32 & 0.0431 & 0.04312 & $\begin{array}{l}A(z)=1-0.5305 z^{-1}+0.03801 z^{-2} \\
B(z)=0.6370 z^{-1}-0.0451 z^{-2}-0.01060 z^{-3}\end{array}$ \\
\hline 3 & ARX321 & 84.33 & 0.0446 & 0.04356 & $\begin{array}{l}\mathrm{A}(\mathrm{z})=1-0.5301 \mathrm{z}^{-1}+0.04501 \mathrm{z}^{-2}+0.004114 \mathrm{z}^{-3} \\
\mathrm{~B}(\mathrm{z})=0.640 \mathrm{z}^{-1}-0.0443 \mathrm{z}^{-2} \\
\mathrm{~A}(\mathrm{z})=1+0.2831 \mathrm{z}^{-1}-0.3101 \mathrm{z}^{-2}\end{array}$ \\
\hline 4 & ARMAX3221 & 84.45 & 0.0445 & 0.0434 & $\begin{array}{l}\mathrm{B}(\mathrm{z})=0.6401 \mathrm{z}^{-1}+0.4721 \mathrm{z}^{-2}+0.0072 \mathrm{z}^{-3} \\
\mathrm{C}(\mathrm{z})=1+0.8061 \mathrm{z}^{-1}+0.1582 \mathrm{z}^{-2}\end{array}$ \\
\hline 5 & ARMAX3441 & 84.56 & 0.0449 & 0.04366 & $\begin{array}{l}\mathrm{A}(\mathrm{z})=1-0.631 \mathrm{z}^{-1}-0.7405 \mathrm{z}^{-2}+0.3981 \mathrm{z}^{-3} \\
\mathrm{~B}(\mathrm{z})=0.6512 \mathrm{z}^{-1}-0.0959 \mathrm{z}^{-2}-0.5401 \mathrm{z}^{-3}+0.01306 \mathrm{z}^{-4} \\
\mathrm{C}(\mathrm{z})=1-0.1190 \mathrm{z}^{-1}-0.7299 \mathrm{z}^{-2}-0.0901 \mathrm{z}^{-3}-0.0520 \mathrm{z}^{-4} \\
\mathrm{~A}(\mathrm{z})=1-0.630 \mathrm{z}^{-1}-0.8001 \mathrm{z}^{-2}+0.4019 \mathrm{z}^{-3}-0.000601 \mathrm{z}^{-4}\end{array}$ \\
\hline 6 & ARMAX4441 & 84.91 & 0.0442 & 0.04432 & $\begin{array}{l}\mathrm{B}(\mathrm{z})=0.6602 \mathrm{z}^{-1}-0.09501 \mathrm{z}^{-2}-0.5291 \mathrm{z}^{-3}+0.01281 \mathrm{z}^{-4} \\
\mathrm{C}(\mathrm{z})=1-0.1202 \mathrm{z}^{-1}-0.801 \mathrm{z}^{-2}-0.0903 \mathrm{z}^{-3}-0.0490 \mathrm{z}^{-4}\end{array}$ \\
\hline
\end{tabular}

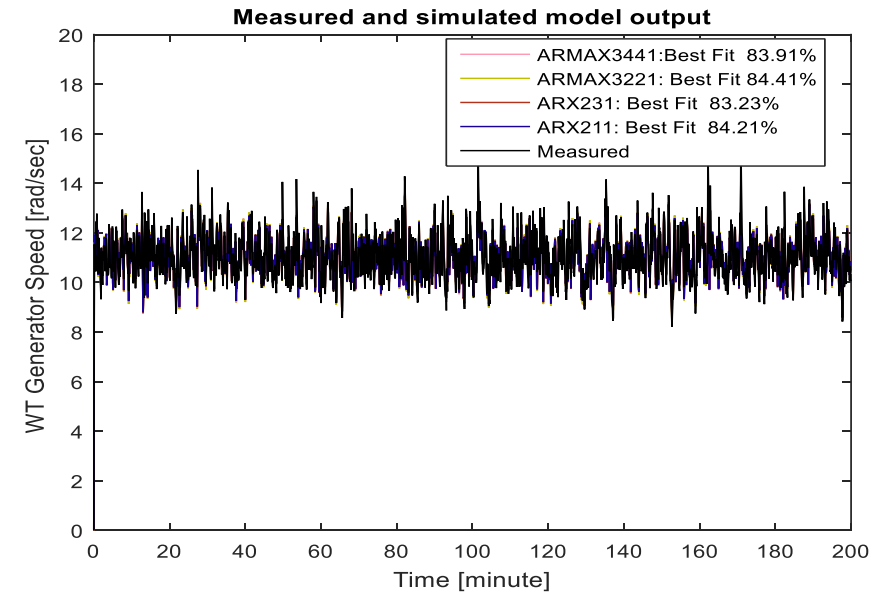

Figure 3. Signals for the model validation of ARX and ARMAX structures.
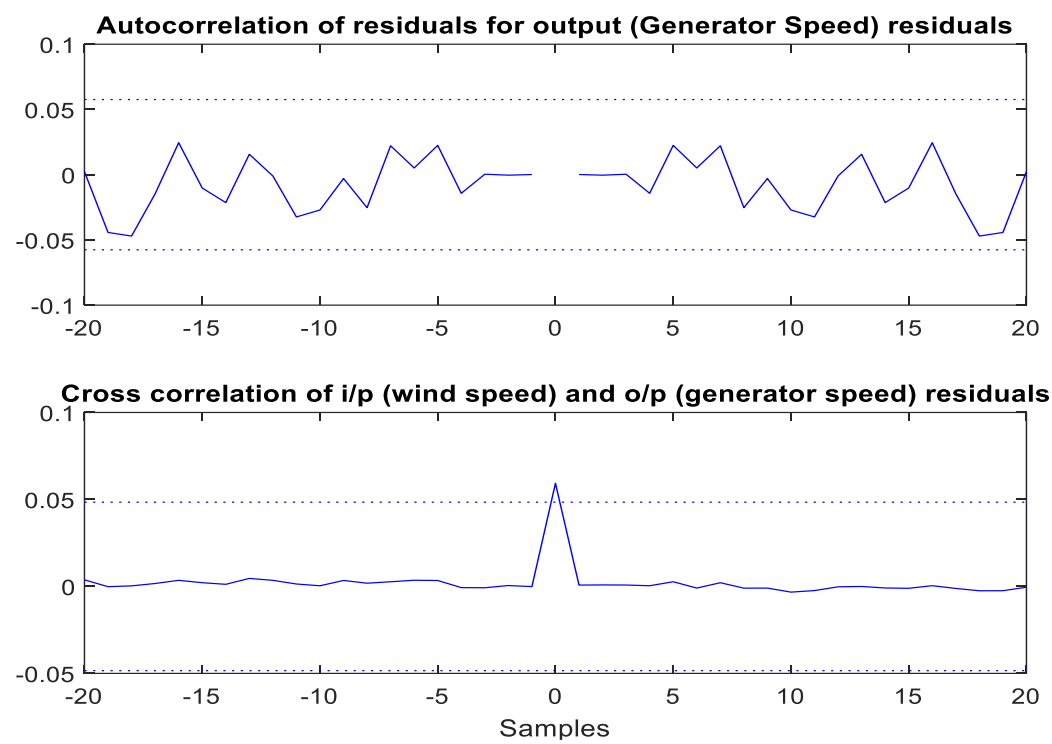

Figure 4. Residual Technique Curves for the WECS Model Validation Test. 
This indicates that the discrete linear model of the WECS is adequate for the mathematical model representation of the system. Fig. 4 shows the autocorrelation of the output and cross-correlation of input and output of the ARX221 model structure of the WECS. The output autocorrelation of the models need to be within a certain range of the equivalent estimate showing the outputs are uncorrelated. It also shows the output residuals are within a certain interval ( -0.1 to 0.1$)$. This proves that the output residuals are uncorrelated and autonomous from previous inputs.

\section{SPEED CONTROLLER DESIGN}

There are two operating modes for the DFIG speed control as discussed in Refs. [16,24]. The first is when the wind is lower than the nominal value. Here, the generator operates at a speed lower than the synchronous speed, where the slip becomes positive. In this case, the power is delivered to the winding of rotor and grid by stator winding. The second mode is when the rotor runs with speed higher than synchronous speed where its slip becomes negative. Here, the power is delivered to the grid through the stator and rotor windings of the generator. Monthly average wind speeds in Table 2 are less than the rated wind speed indicating the generator operates in the first mode. The speed controller is designed for the model formulated in Eq. (7b). Fig. 5 shows the simulation results of the model. In this figure, when unit step input is applied, it is observed that the generator speed exhibits undershoot in transient response and its steady-state response is maintained at 1.14 per unit (p.u). The rated speed of the generator is considered as $1680 \mathrm{rpm}$, which means the generator is above the rated speed by $235 \mathrm{rpm}$. This may result in frequency or power instability.

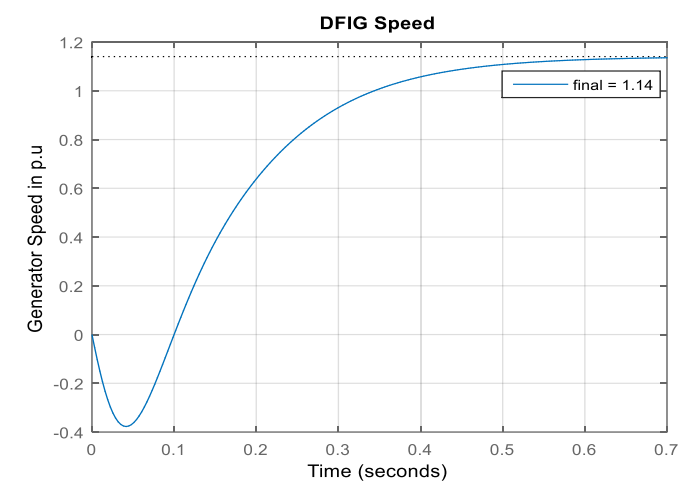

Figure 5. Uncontrolled generator speed at the rated wind speed of $9.5 \mathrm{~m} / \mathrm{s}$ equal to 1 p.u for the WECS model.

Since the real wind speed is time varying, the generator speed controller parameters should be selfadjustable to regulate the generator speed around its rated value. In this research, PID controller based on fuzzy logic and Ziegler-Nichols method are improved for the generator speed control. We employ PID controller by adapting its parameters by using fuzzy logic to achieve the aim of the study. Fig. 6 depicts the proposed diagram for the fuzzy logic-based controller. Classical methods for the PID controller parameter tuning cannot attain acceptable response for the WECS because of its nonlinearity and irregular uncertainty varying with the wind speed. Therefore, fuzzy logic-based updating technique for the PID controller is developed and evaluated in the present work. The general continuous-time PID model, as discussed in [25], is adapted and merged with fuzzy logic. This is expressed by,

$$
P I D=K_{p} e(t)+\frac{1}{\tau_{I}} \int_{t_{o}}^{t} e(\tau) d \tau+\tau_{d} \frac{d e(t)}{d t}
$$

Here the proportional gain is $K_{P}$, the derivative time constant is $T_{d}=K_{d} / K_{p}$, and the integral time constant is $T_{I}=\gamma T_{d}$. For the proposed controller structure shown in Fig. 6, the error $e(t)$ between the reference input and system actual output, and the rate of change of the error (i.e. $d e(t) / d t$ ) are the inputs. The fuzzy 
inference is intended to update 3 parameters of the PID controller $[26,27,28]$ as depicted in Fig. 7 . The fuzzy inference generates nonlinear relations from its inputs (i.e. $e(t)$ and $d e(t) / d t)$ ) to the PID controller parameters $\left(K_{p}, K_{d}, \gamma\right)$. These relations or rules are planned to obtain the appropriate response of generator speed in WECS. The maximum / minimum aggregation of fuzzy sets and centroid defuzzification are employed for this controller design.

To develop a self-updating fuzzy logic-based PID controller the domains of its parameters are decided based on their specific values obtained by applying the Ziegler-Nichols (Z-N) graphical method [29,30] on considering the performance and stability of the system. Hence, based on Z-N graphical method the coefficients $K_{p}=1.18, K_{i}=19.4$ at $\gamma=4$ and $K_{d}=0.018$ are found for this system. For the self-updating fuzzy logic-based PID controller, before the normalization, $K_{p}$ is between 0 and 1.2, $K_{d}$ ranges from 0 to 0.02 , and $\gamma=\gamma^{\prime}$ which ranges between 1 and 6 . The values of $K_{p}$ and $K_{d}$ are normalized to $K_{P}^{\prime}$ and $K_{d}^{\prime}$ in the range of 0 and 1 as shown in Fig. 8.

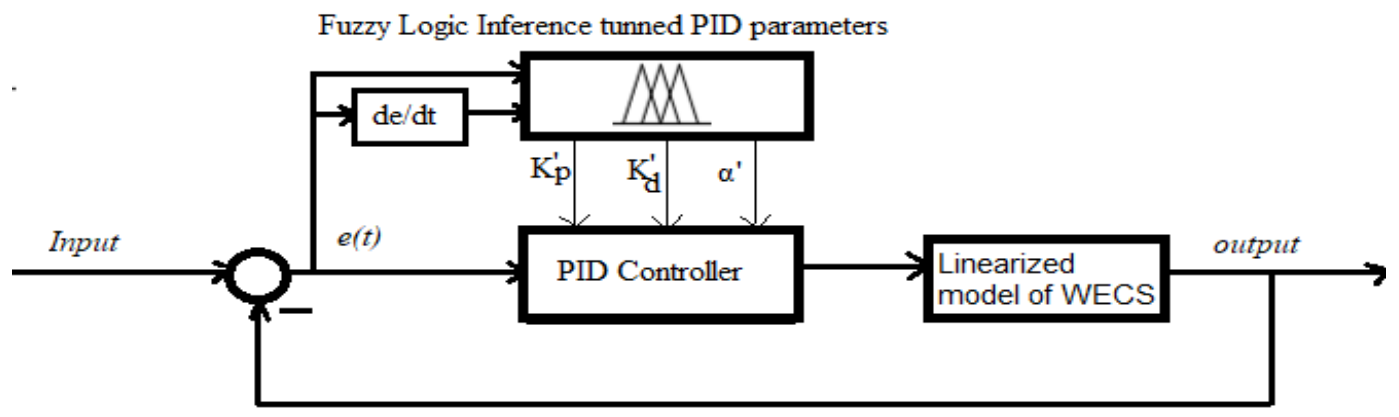

Figure 6. The proposed structure for self-updating PID Controller.

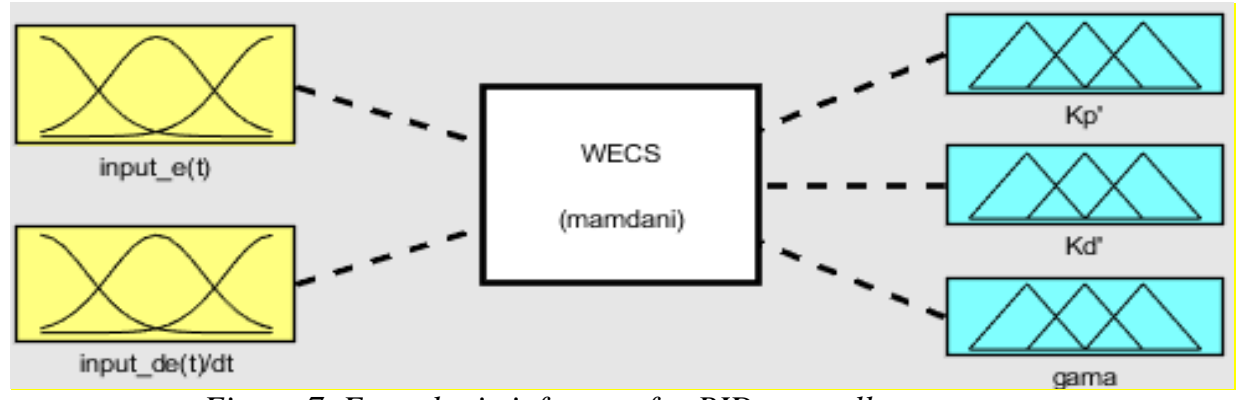

Figure 7. Fuzzy logic inference for PID controller structure.

The designed fuzzy logic-based continuous-time PID controller has the form as shown in Eq. (9) and depicted in Fig. 8. In this figure, the rate of variation of error input to the fuzzy logic is described by unit delay and derivative filter. The coefficient $N$ is associated with the PID controller to reduce the noise due to the derivative parameter of the controller. The normalized ranges of PID controller parameters are equivalently expressed as the values generated by fuzzy logic as in Eqs. (10a - 10c).

$$
\begin{gathered}
\mathrm{PID}=\left(0.2 \mathrm{~K}_{\mathrm{P}}^{\prime}+1\right) e(t)+\left(10 \frac{\left(\mathrm{K}_{\mathrm{p}}^{\prime}\right)^{2}}{\gamma \mathrm{K}_{\mathrm{d}}^{\prime}}+17.73\right) \int_{t o}^{t} e(\tau) d \tau+\left(\frac{\mathrm{K}_{\mathrm{d}}^{\prime}}{125}+0.01\right) \frac{d e(t)}{d t} \\
K_{P}=0.2 \mathrm{~K}_{\mathrm{P}}^{\prime}+1 \\
K_{I}=10 \frac{\left(K_{P}^{\prime}\right)^{2}}{\gamma K_{d}^{\prime}}+17.73 \\
K_{d}=\frac{\mathrm{K}_{\mathrm{d}}^{\prime}}{125}+0.01
\end{gathered}
$$




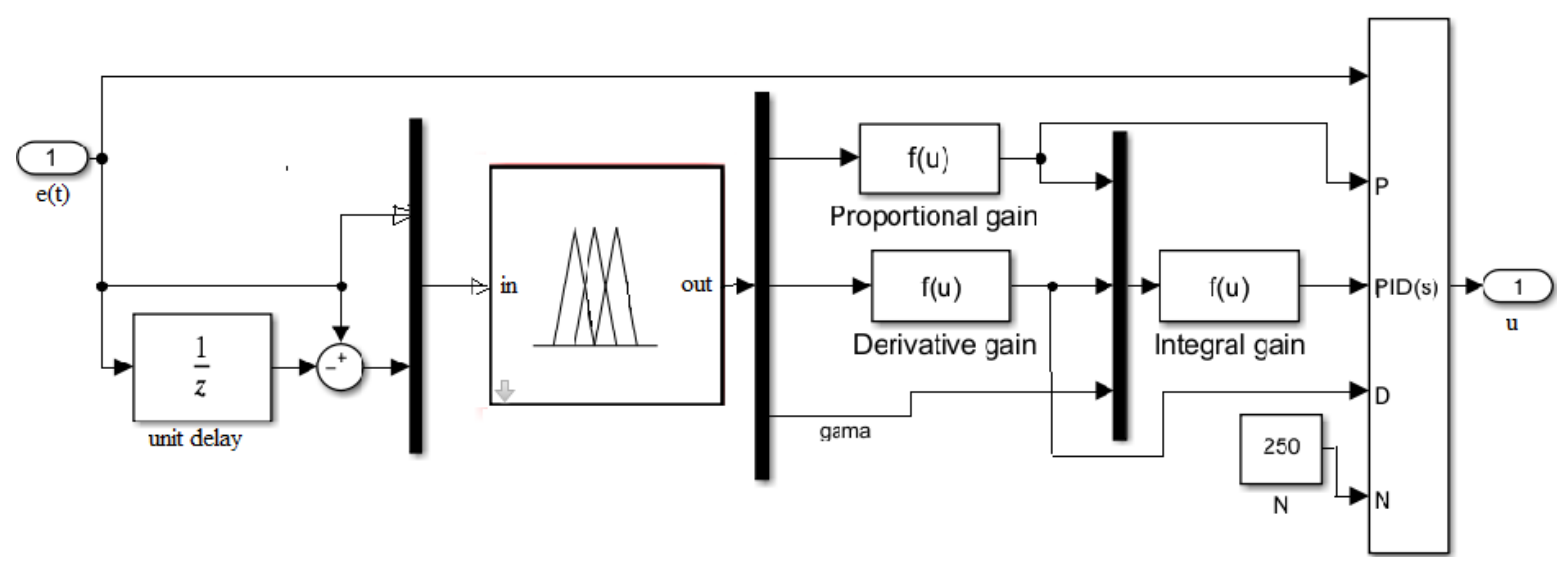

Figure 8. Fuzzy logic based PID controller structure.

The membership functions for $e(t)$ and $d e(t) / d t$ are triangular shapes within the range of $[-1,1]$. Moreover, their membership function are triangular as depicted in Figs. 9(a,b). The linguistic equivalence of $e(t)$, and $d e(t) / d t$ are set with 7 terms for each: Large negative (LN), medium negative (MN), small negative (SN), zero (Z), small positive (SP), medium positive (MP), and large positive (LP). Figs. 9(c,d) show the $K_{P}^{\prime}$ and $K_{d}^{\prime}$ parameters with Gaussian membership functions. For $K_{P}^{\prime}$ and $K_{d}^{\prime}$, the linguistic terms small (S) and large (L) are assigned. The linguistic terms assigned to $\gamma$ have the same with numeric values as illustrated in Fig. 9(e). In total, 49 "if $e$ is _ and de/dt is _ then $K_{p}^{\prime}$ is _ and $K_{d}^{\prime}$ is _ and $\gamma^{\prime}$ is _ " fuzzy rules are used for generator speed control of the WECS. These rules are given in Tables $4,5 \overline{\text { in }}$ detail.

Table 4. Rules to tune $K_{P}^{\prime}$ and $K_{d}^{\prime}$ components of the PID controller

\begin{tabular}{|c|c|c|c|c|c|c|c|c|c|c|c|c|c|c|}
\hline \multirow{3}{*}{$e(t)$} & \multicolumn{7}{|c|}{$K_{P}^{\prime}$} & \multicolumn{7}{|c|}{$K_{d}^{\prime}$} \\
\hline & \multicolumn{7}{|c|}{ Change in Error $(d e(t) / d t)$} & \multicolumn{7}{|c|}{ Change in Error $(d e(t) / d t)$} \\
\hline & $\mathrm{LN}$ & MN & SN & $\mathrm{Z}$ & $\mathrm{SP}$ & MP & $\mathrm{LP}$ & LP & MN & SN & $\mathrm{Z}$ & SP & MP & LP \\
\hline LN & $\mathrm{L}$ & $\mathrm{S}$ & $\mathrm{S}$ & $\mathrm{S}$ & $\mathrm{S}$ & $\mathrm{S}$ & $\mathrm{L}$ & $\mathrm{S}$ & $\mathrm{L}$ & $\mathrm{L}$ & $\mathrm{L}$ & $\mathrm{L}$ & $\mathrm{L}$ & $\mathrm{S}$ \\
\hline $\mathrm{MN}$ & $\mathrm{L}$ & $\mathrm{L}$ & $\mathrm{S}$ & $\mathrm{S}$ & $\mathrm{S}$ & $\mathrm{L}$ & $\mathrm{L}$ & $\mathrm{S}$ & $\mathrm{L}$ & $\mathrm{L}$ & $\mathrm{L}$ & $\mathrm{L}$ & $\mathrm{L}$ & $\mathrm{S}$ \\
\hline SN & $\mathrm{L}$ & $\mathrm{L}$ & $\mathrm{L}$ & $\mathrm{L}$ & $\mathrm{L}$ & $\mathrm{L}$ & $\mathrm{L}$ & $\mathrm{S}$ & $\mathrm{S}$ & $\mathrm{L}$ & $\mathrm{L}$ & $\mathrm{L}$ & $\mathrm{S}$ & $\mathrm{S}$ \\
\hline $\mathrm{Z}$ & $\mathrm{L}$ & $\mathrm{L}$ & $\mathrm{L}$ & $\mathrm{L}$ & $\mathrm{L}$ & $\mathrm{L}$ & $\mathrm{L}$ & $\mathrm{S}$ & $\mathrm{S}$ & $\mathrm{L}$ & $\mathrm{L}$ & $\mathrm{S}$ & $\mathrm{S}$ & $\mathrm{S}$ \\
\hline SP & $\mathrm{L}$ & $\mathrm{L}$ & $\mathrm{L}$ & $\mathrm{S}$ & $\mathrm{L}$ & $\mathrm{L}$ & $\mathrm{L}$ & $\mathrm{S}$ & $\mathrm{S}$ & $\mathrm{L}$ & $\mathrm{L}$ & $\mathrm{L}$ & $\mathrm{S}$ & $\mathrm{S}$ \\
\hline MP & $\mathrm{L}$ & $\mathrm{L}$ & $\mathrm{S}$ & $\mathrm{S}$ & $\mathrm{S}$ & $\mathrm{L}$ & $\mathrm{L}$ & $\mathrm{S}$ & $\mathrm{L}$ & $\mathrm{L}$ & $\mathrm{L}$ & $\mathrm{L}$ & $\mathrm{L}$ & S \\
\hline LP & $\mathrm{L}$ & $\mathrm{S}$ & $\mathrm{S}$ & $\mathrm{S}$ & $\mathrm{S}$ & $\mathrm{S}$ & $\mathrm{L}$ & $\mathrm{S}$ & $\mathrm{L}$ & $\mathrm{L}$ & $\mathrm{L}$ & $\mathrm{L}$ & $\mathrm{L}$ & $\mathrm{S}$ \\
\hline
\end{tabular}

Table 5. Rules to tune $\gamma$ component of PID controller

\begin{tabular}{llllllll}
\hline & \multicolumn{7}{l}{ Change in Error $(d e(t) / d t)$} \\
\cline { 2 - 7 } & LN & MN & SN & Z & SP & MP & LP \\
\hline LN & 2 & 3 & 4 & 5 & 4 & 3 & 2 \\
MN & 2 & 3 & 3 & 4 & 3 & 3 & 2 \\
SN & 2 & 2 & 3 & 3 & 3 & 2 & 2 \\
Z & 2 & 2 & 2 & 3 & 3 & 2 & 2 \\
SP & 2 & 2 & 3 & 3 & 3 & 2 & 2 \\
MP & 2 & 3 & 3 & 4 & 3 & 3 & 2 \\
LP & 2 & 3 & 4 & 5 & 4 & 3 & 2 \\
\hline
\end{tabular}



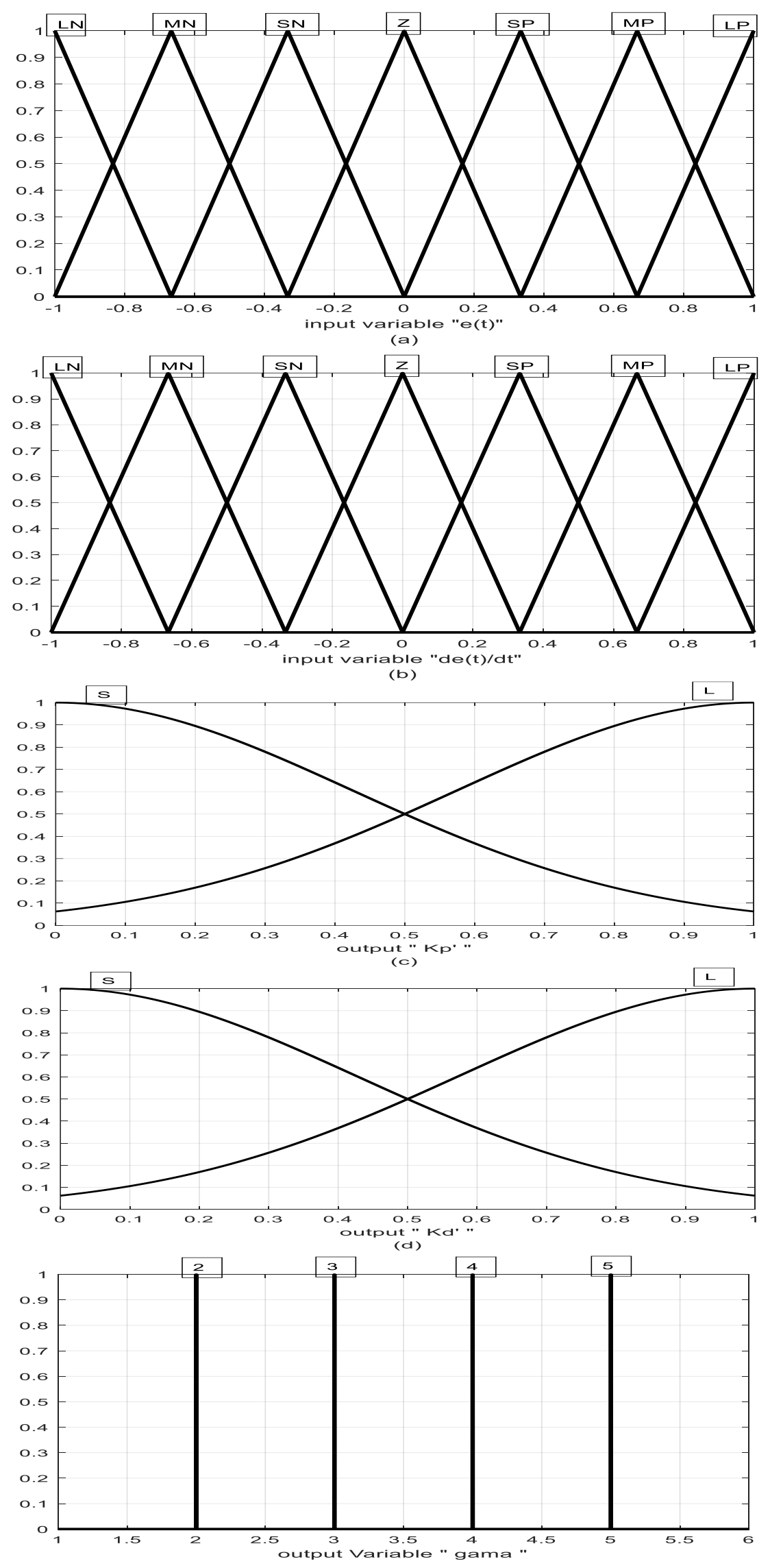

Figure 9. Fuzzy logic membership functions for (a) Error, (b) de(t)/dt, (c) $K_{P}^{\prime},(d) K_{d}^{\prime}$ and (e) $\gamma$. 
For the MatLab/Simulink simulation, the block diagram of the estimated WECS model with the proposed controllers shown in Fig. 8 is connected together as depicted in Fig. 10 to Fig. 13. These are the plots of the simulation results.

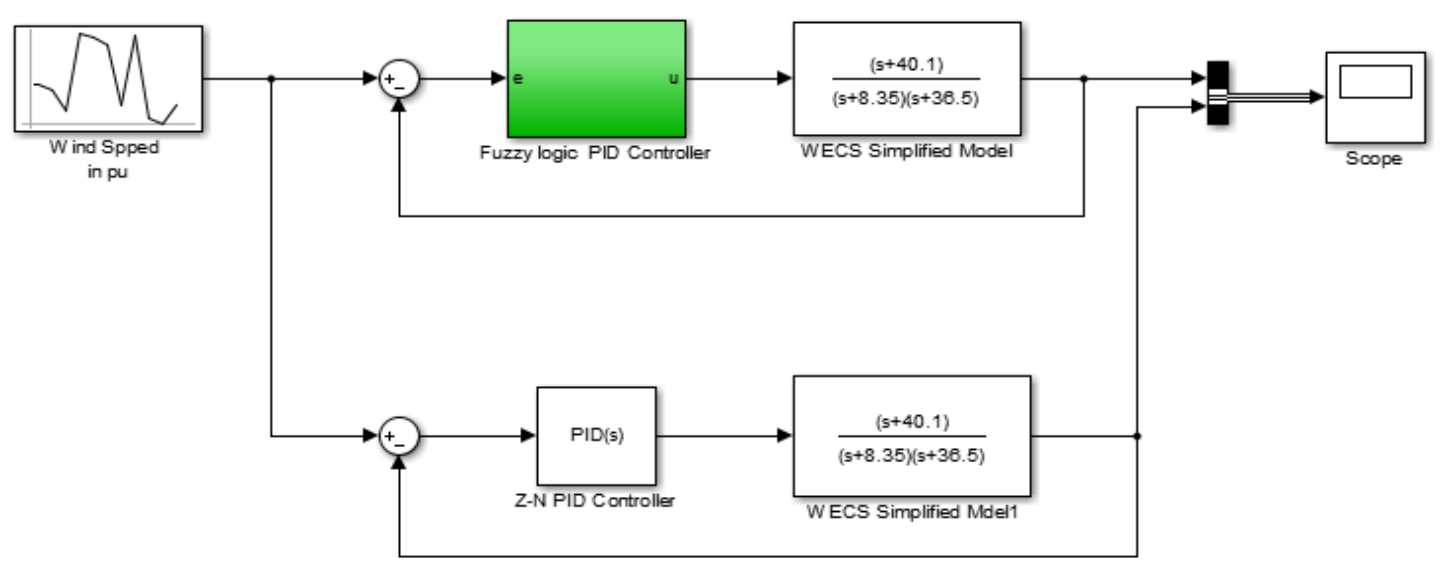

Figure 10. Simulink block of fuzzy logic-based PID and classical Z-N PID Controllers of the generator speed in WECS.

\section{RESULTS AND DISCUSSION}

The simulation results are generated for the nominal model of the WECS generator speed controllers. Step input is assumed as per unit value of uniform and rated wind speed. From Table 2, actual annual average wind speed of $9.74 \mathrm{~m} / \mathrm{s}$, equivalently $1 \mathrm{p} . \mathrm{u}$ with variance of $0.5 \mathrm{~m} / \mathrm{s}$ and $0.2 \mathrm{~m} / \mathrm{s}$ is used as the input to Fig. 10 to test the designed PID controllers based on Z-N method and Fuzzy logic. The results are presented in Table 6 and in Fig. 11 through Fig 13.

Table 6. DFIG based WECS speed response when controlled by the PID controller

\begin{tabular}{|c|c|c|c|c|}
\hline \multirow[b]{2}{*}{ Method } & \multirow{2}{*}{$\begin{array}{l}\text { Input is } 1 \text { p.u with } \\
\text { variance of }\end{array}$} & \multicolumn{3}{|c|}{ Response Performance Indicators } \\
\hline & & $\begin{array}{l}\text { Settling time } \\
\text { (s) }\end{array}$ & Overshoot /sluggish & Steady state value \\
\hline $\mathrm{Z}-\mathrm{N}$ & \multirow{2}{*}{ \pm 0} & $<1$ & $25 \%$ & 0.8 p.u $=1344 \mathrm{rpm}$ \\
\hline Fuzzy Logic & & $<1$ & $2 \%$ & 1 p.u $=1680 \mathrm{rpm}$ \\
\hline $\mathrm{Z}-\mathrm{N}$ & \multirow{2}{*}{ \pm 0.5} & $>10$ & sluggish & $0.8 \mathrm{p} . \mathrm{u}=1344 \mathrm{rpm}$ \\
\hline Fuzzy Logic & & $<1$ & Varying around 1p.u & 1 p.u =1680 rpm \\
\hline $\mathrm{Z}-\mathrm{N}$ & \multirow{2}{*}{ \pm 0.2} & $>10$ & sluggish & 0.88 p.u $=1478 \mathrm{rpm}$ \\
\hline Fuzzy Logic & & $<0.5$ & around $1 \mathrm{p} . \mathrm{u}$ & $1 \mathrm{p} . \mathrm{u}=1680 \mathrm{rpm}$ \\
\hline
\end{tabular}

The result in Table 6 indicates that the speed response of DFIG based WECS maintained the steady state value with less than $1 \mathrm{~s}$, when the PID controller is fuzzy logic tuned and even under varying inputs. On the other hand, it takes $10 \mathrm{~s}$ in case of classical PID with variable inputs. Table 6 and Fig. 11 show the response of the speed of WECS controlled by both the Z-N method PID controller and the fuzzy logicbased updatable PID controller, when the unit step (rated speed) input signal is applied. The fuzzy logicbased PID controller attains better output, when compared with the PID controller designed by the Z-N method. Both responses of the controllers have less than $1 \mathrm{~s}$ settling time. Nevertheless, when Z-N PID is used, the system response exhibited $25 \%$ overshoot and maintained a final value of 0.8 p.u. The fuzzy logic-based PID controller has an overshoot of less than $2 \%$ and final value of 1 p.u. This indicates that the generator runs at its rated speed for uniform and rated value inputs wind speed to the WECS, when the fuzzy logic-based PID controller is employed. For classical Z-N PID controller case, the generator runs at $1344 \mathrm{rpm}$ below its rated speed even though the wind speed is uniform and at the rated value. This causes lower power capture from wind resulting in generator overloading and frequency instability in the case of a grid-connected wind turbine unit. 


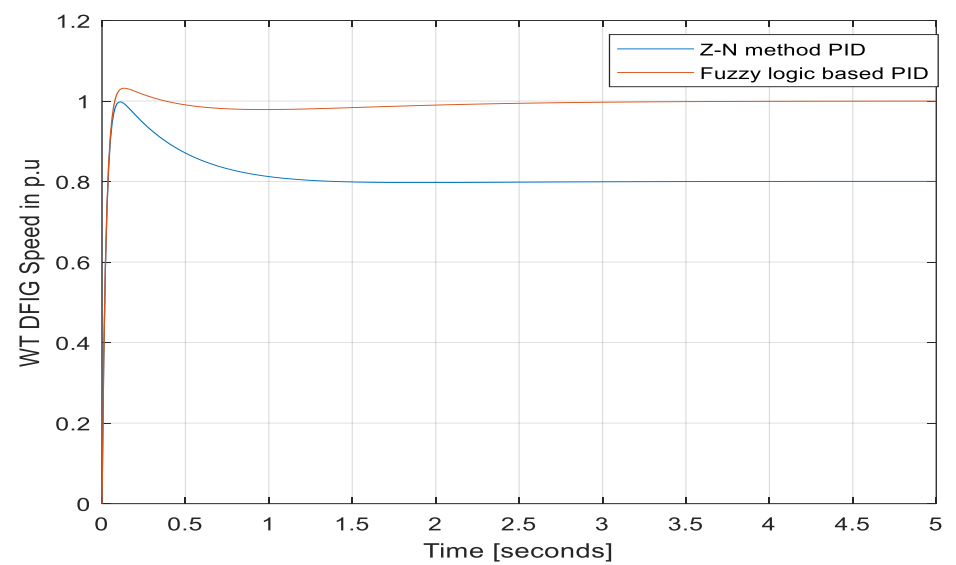

Figure 11. Z-N PID and Fuzzy logic-based PID controlled generator speed response at wind speed of $13 \mathrm{~m} / \mathrm{s}$ (equivalent to 1 p.u) is used as the input.

The simulation results shown in Figs. 12,13 are generated when 1 p.u. with 0.5 or 0.2 variances is applied to the system. When the Z-N method PID controls the speed of the DFIG generator, the steady-state value is 0.8 p.u as in Table 6 and Fig. 12 and 0.88 p.u as Table 6 and in Fig. 13 that is 1344 rpm and $1478 \mathrm{rpm}$, respectively. These are for the same rated wind speed input with different variations. These responses are sluggish as indicated in Figs. 12,13. However, when the fuzzy logic-based PID controller is used, the generator speed is settled to its rated value with in one second. This response is higher than the results presented in Refs. [31,32] even under variable input with smaller variation as seen in Fig. 13. This is achieved since the PID parameters are self-updatable by fuzzy logic under the stated conditions. This shows that the classical PID controller is not as good as the fuzzy logic-based PID for a system with variable inputs.

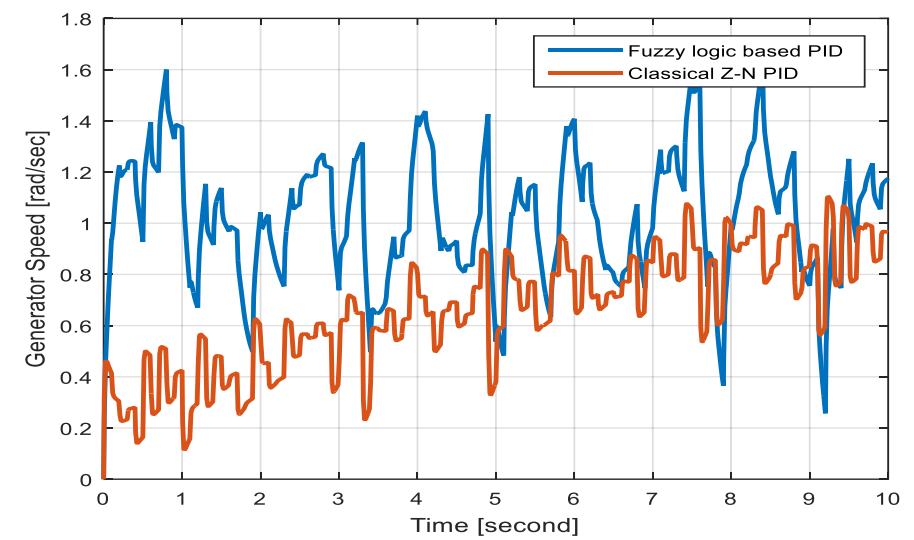

Figure 12. Z-N method PID and Fuzzy logic based PID controlled generator speed response for real-time data of annual average of 1 p.u with 0.5 variance wind speed as presented in Table 1.

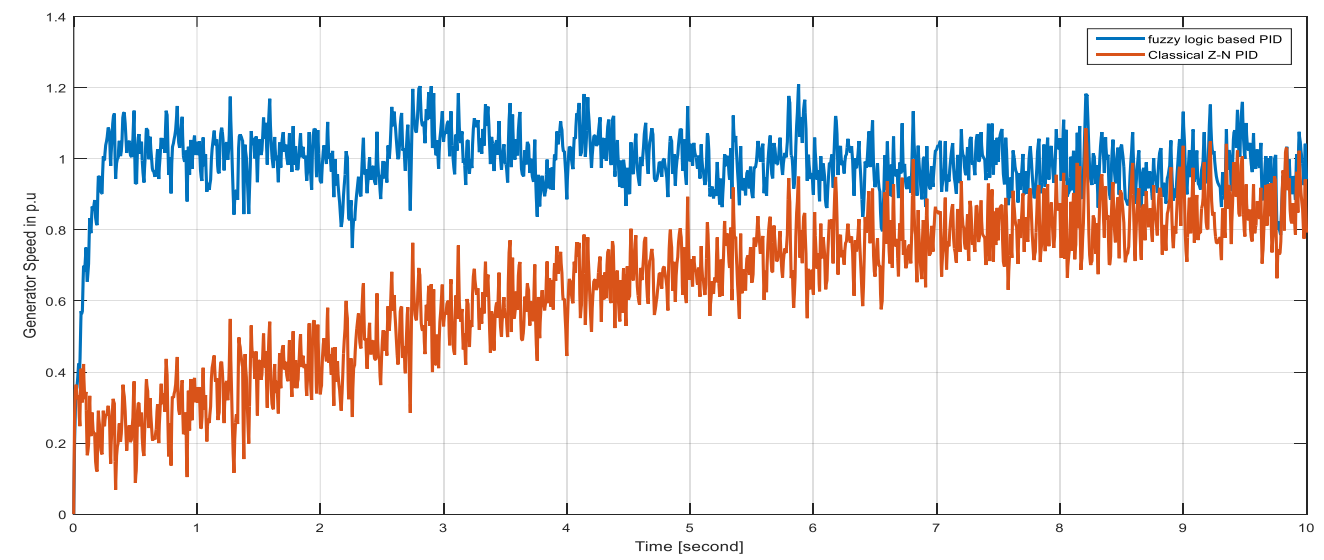

Figure 13. Z-N method PID and fuzzy logic-based PID controlled generator speed response for the real-time data of annual average of 1 p.u with $0.2 \mathrm{~m} / \mathrm{s}$ variance wind speed presented in Table 1. 


\section{CONCLUSIONS}

The System Identification Toolbox of MatLab is used to develop the linear model of the WECS relating wind speed with generator speed. Different ARX and ARMAX models are developed. The performances of the ARMAX and the ARX models are closely related. However, the ARMAX model structures are found to be more complex than the ARX. Hence, we used the ARX221 model structure with best fit of $84.31 \%, 0.0433 \mathrm{FPE}$, and $0.0432 \mathrm{MSE}$ for the controller design due to its simplicity. The model validity is carried out according to the residual correlation criterion. The Z-N method and fuzzy logic based PID controllers are used to control the DFIG generator speed in WECS. When classical Z-N PID is used, the response of the system is not satisfactory for both uniform and variable inputs. For the fuzzy logic-based PID controller, the generator speed is around its rated value and the response is improved under uniform and even for variable wind speeds. This is due to the PID parameters are self-updatable by fuzzy logic under the stated conditions. Power regulation, frequency stability, and load variation impacts are possible future extension to improve WECS modelling and performance.

\section{Acknowledgments}

We acknowledge the professionals working at Adama wind farm owned by the Government of Ethiopia for providing the real-time wind speed data used in this research work.

\section{REFERENCES}

[1] Solberg O. A New Wind Turbine Control Method to Smooth Power Generation - Modelling and Comparison to Wind Turbine Frequency Control (MSc). Chalmers University of Technology, Sweden, 2012.

[2] Billings SA, Chen S, Korenberg MJ. Identification of MIMO non-linear systems using a forward-regression orthogonal estimator. International journal of control 1989; 49(6): 2157-2189.

[3] Subudhi B, Ogeti PS. Non-linear autoregressive moving average with exogenous input model-based adaptive control of a wind energy conversion system. The Journal of Engineering 2016; 2016(7): 218-226.

[4] Johansen TA, Foss B. Constructing NARMAX models using ARMAX models. International journal of control 1993; 58(5): 1125-1153.

[5] Bekker JC. Efficient modelling of a wind turbine system for parameter estimation applications $(\mathrm{PhD})$, Stellenbosch University, Stellenbosch, South Africa, 2012.

[6] Cadenas E, Rivera W. Wind speed forecasting in three different regions of Mexico using a hybrid ARIMAANN model. Renewable Energy 2010; 35(12): 2732-2738.

[7] Perez-Llera C, Fernandez-Baizan MC, Feito JL, González del Valle V. Local short-term prediction of wind speed: a neural network analysis. In: $1^{\text {st }}$ International Congress on Environmental Modelling and Software; 24-27 June 2002, Switzerland: Brigham Young University Scholars Archives, pp.124-129.

[8] Nur Dalila Binti Khirul Ashar, Zakiah Mohd Yusoff, Nurlaila Ismail, Muhammad Asraf Hairuddin. ARX Model Identification for the Real-Time Temperature Process with MATLAB-ARDUINO Implementation. ICIC Express Letter 2020; 14(2): 103-111.

[9] MATLAB R2020b Documentation - System Identification Toolbox, Accessed from https://www.mathworks.com/help/ident/?s_tid=srchbrcm, Accessed on October 2020.

[10] Muhammad Junaid Rabbani, Kashan Hussain, Asim-ur-Rehman khan, Abdullah Ali. Model Identification and Validation for a Heating System using MATLAB System Identification Toolbox, 2013 IOP Conf. Ser.: Mater. Sci. Eng.51 012022.

[11] Vijayalaxmi1, Shanmuga Vadivoo. Identification of Doubly Fed Induction Generator based Wind Energy Conversion System Using Piecewise-Linear Hammerstein Wiener Model, Proceedings of $7^{\text {th }}$ International Conference on Intelligent Systems and Control 2013: 37 - 43.

[12] Lin WM, Hong CM, Cheng FS. On-line designed hybrid controller with adaptive observer for variable-speed wind generation system. Energy 2010, 35(7): 3022-3030.

[13] Barambones O, de Durana JG, De la Sen M. Robust speed control for a variable speed wind turbine. International Journal of Innovative Computing, Information and Control 2012, 8(11):7627-7640.

[14] Munteanu I, Bratcu AI, Cutululis NA, Ceanga E. Optimal control of wind energy systems: towards a global approach. London, England: Springer-Verlag London, 2008.

[15] Aroussi HA, Ziani E, Bossoufi B. Speed control of the doubly fed induction generator applied to a wind system. Journal of Theoretical and Applied Information Technology 2016; 83(3): 426-433. 
[16] Osmic J, Kusljugic M, Becirovic E, Toal D. Analysis of active power control algorithms of variable speed wind generators for power system frequency stabilization. Turkish Journal of Electrical Engineering \& Computer Sciences 2016; 24(1): 234-246.

[17] Jalali M. DFIG based wind turbine contribution to system frequency control (MSc). University of Waterloo, Ontario, Canada, 2011.

[18] Adel Ab-BelKhair, Javad Rahebi, Abdulbaset Abdulhamed Mohamed Nureddin. A Study of Deep Neural Network Controller-Based Power Quality Improvement of Hybrid PV/Wind Systems by Using Smart Inverter. International Journal of Photoenergy2020, 2020.

[19] Abdulbaset Abdulhamed Mohamed Nureddin, Javad Rahebi, Adel Ab-BelKhair. Power Management Controller for Microgrid Integration of Hybrid PV/Fuel Cell System Based on Artificial Deep Neural Network. International Journal of Photoenergy 2020, 2020.

[20] Yasmine Ihedrane, Chakib El Bekkali, Badre Bossoufi, Manale Bouderbala. Control of Power of a DFIG Generator with MPPT Technique for Wind Turbines Variable Speed. In: Modelling, Identification and Control Methods in Renewable Energy Systems, Green Energy and Technology 2019; Springer Nature Singapore Pte Ltd., N. Derbel, Q. Zhu (eds.), pp. 105-127.

[21] Hassane Mahmoudi, Marouane El Azzaoui, Chafik Ed-Dahmani. Zed Board-FPGA Control of the DFIG Based Wind Power System. In: Modeling, Identification and Control Methods in Renewable Energy Systems, Green Energy and Technology 2019; Springer Nature Singapore Pte Ltd., N. Derbel, Q. Zhu (eds.), pp. 333 -355 .

[22] Abdelbaset A, Mohamed YS, El-Sayed AH, Ahmed AE. Wind Driven Doubly Fed Induction Generator: Grid Synchronization and Control. Geneva, Switzerland: Springer International Publishing, 2018.

[23] Vestas. General Specification V90-1.8/2.0 MW 50 Hz VCS: Document no.: 0004-6207 V05. Copenhagen, Denmark: Vestas Wind Systems A/S, 2010.

[24] Simões, M. Godoy, Farret, A. Felix. Renewable Energy Systems: Design and Analysis with Induction Generators. California, USA: CRC Press, 2004.

[25] Atacak I, Küçük B. PSO-Based PID Controller Design for an Energy Conversion System Using Compressed Air. Tehnicki Vjesnik/Technical Gazette 2017, 24(3): 671-679.

[26] Woo ZW, Chung HY, Lin JJ. A PID type fuzzy controller with self-tuning scaling factors. Fuzzy sets and systems 2000, 115(2): 321-326.

[27] Güzelkaya M, Eksin I, Yeşil E. Self-tuning of PID-type fuzzy logic controller coefficients via relative rate observer. Engineering applications of artificial intelligence 2003, 16(3): 227-236.

[28] Qiao WZ, Mizumoto M. PID type fuzzy controller and parameters adaptive method. Fuzzy sets and systems 1996, 78(1), 23-35.

[29] Jantzen J. Tuning of fuzzy PID controllers. In Rames C. P., Introduction to PID Controllers - Theory, Tuning and Application to Frontier Areas, Technical University of Denmark, Denmark: IntechOpen, 1998, 171-190.

[30] Ogata K. Modern Control Engineering: Mathematical Modelling of Control Systems. New Jersey, USA: Prentice Hall, 2010.

[31] Nadhir A, Naba A, Hiyama T. FIS/ANFIS based optimal control for maximum power extraction in variablespeed wind energy conversion system. IEEJ Transactions on Power and Energy 2011; 131(8): 708-714. DOI: 10.1541/ieejpes. 131.708

[32] Aydin E, Polat A, Ergene LT. Vector control of DFIG in wind power applications. In: IEEE International Conference on Renewable Energy Research and Applications (ICRERA); Nov 20 2016: IEEE, pp. 478-483. 